Journal of Education and Vocational Research

Vol. 2, No. 3, pp. 116-119, Sep 2011 (ISSN 2221-2590)

\title{
Student Counseling: Adding Value to Educational Institution
}

\author{
*Rashid Mehmood, Salima Hafeez, Mubashir Hussain, Ali Iftikhar Chaudhry, Kashif-ur-Rehman \\ Iqra University Islamabad, Pakistan \\ *chaoudhry1@yahoo.com
}

\begin{abstract}
Quality of education has always remained an issue for the educational researchers. It is widely believed that quality of education in Sub-Continent is below the international standards. To find out how educational institutions are adding value towards the knowledge, skills, market value and moral upbringing of students and how much students are satisfied with the environment of educational system and the quality of education they receive.Using this information, how a student counseler can benefit the student as well the organization to add value in the education process. This is a case study where a Govt. Intermediate College was selected for interviews and document analysis purpose. Findings based on general perception of the respondents, All the respondents have matriculated from Public School. The findings showed that students were really concerned about the poor discipline of their schools and generally they were not satisfied with the commitment and capability of their teachers. However, they admitted that school contributed towards their grooming and personality building.
\end{abstract}

Keywords: Value Addition, Students Counseling, Quality Education, Literacy Rate,

\section{Introduction}

Education is one of the basic necessities of a human. People are more conscious about the quality of education. Due to Poor economic system and more spending on the basic needs, quality of education is not affordable for every human being. As the history of counseling in schools is concerned, it dates back to the work of pioneering headmasters in late eighteenth century. First child psychologist was appointed in 1913 while the first clinic for the guidance for children was established in 1921. However, it is believed that first child counseling services in USA in 1950s while it started in UK in 1960s Unfortunately, Pakistan lags far behind, after more than 60 years of its creation, both in quantity and quality of education. Education was declared as matter of life or death by the founding father of Pakistan and successive governments pledged their commitment towards quality and quantity of education. While in sub-continent Sri Lanka and India provide variety of quality education to their people.

It is widely believed that educational system of Pakistan is not at par with that of other countries and it is not fulfilling its very purpose. But little serious effort has so far been made and rhetoric's of politicians have never been backed by strong political-will and far sighted vision. Moreover, there is no culture of research studies to explore the depth of problem and to identify the core issues. Policies are made in close rooms with no knowledge of ground realities. No one takes pain to know what people feel about the issue. So it is imperative to dig the issue deep and to learn the scope and depth of the problem. Student counseling at secondary level is very important, because it is the level where student needs a way to choose. Where they should go, someone must be there to guide them. So policy maker must have to devise such a strategy that they can use the hidden talent for the benefit of Pakistan and the world as well. Purpose of this study is to find out weak areas in educational system of Pakistan, so that corrective measure can be taken to overcome those weaknesses.

\section{Literature Review}

Counseling at workplace or in educational institutions helps organizations in motivating the employees /students, enhance performance and resolving the conflict. There are numerous models that, how a counselor can help the organization. To understand the importance of the role of counselor, one can judge by the variety of titles and names that counselors adopt. It shows the importance and complexity of the nature of their job e.g. stress management counselor, occupational health welfare counselor, occupational welfare officer, employee counselor, employee support adviser, employee assistance adviser, and work-life balance officer, face-to-face 
counselor, online counselor, health and work-life balance promoter and group facilitator etc. One study showed that face-to-face counseling is far more effective than online counseling with regard to levels of empathy, selfdisclosure and degree of processing depth. However, another study concluded that online or web counseling is having certain benefits over face to face counseling. Clients are freer to expose their problems and counselor is at more convenience to explore the problems of client in a more objective and result oriented manner. It has been observed that most of college students dare not to visit a counselor due to lack of confidence, obsession with their psychological problems and diffidence in their personality or the secret nature of their specific problems. Therefore, with the development of computer and web based technology, it has become easy and possible to reach out to such students and get an insight of their problems. It has provided us an avenue for consultation in such matters.

As the history of counseling in schools is concerned, it dates back to the work of pioneering headmasters in late eighteenth century. First child psychologist was appointed in 1913 while the first clinic for the guidance for children was established in 1921. However, it is believed that first child counseling services in USA in 1950s while it started in UK in 1960s. McCarthy (1993) reported due to least priority of the guidelines and counseling to the rural areas has been a problem which needs the attention in where schools generally have less than 350 students, and/or where students attend vocational schools. The counselors who are generally recruited for the guidance are mostly hired from the ranks of serving second-level teachers and must have a minimum of three years teaching experience Typically, they have a primary degree in arts or commerce (O'Connor \& Walshe, 1979) and they usually complete an additional one-year full-time post-graduate diploma course in guidance counseling at a third-level institution. The proper establishment of a guidance and counseling service has been credited to a number of factors including the fast industrialization that took place in Ireland during the 1960s, a slowing down in mass departure, and the availability of a wider range of careers for young people (Chamberlain, 1983). Whatever factors outside the educational system gave rise to its introduction, the idea of providing guidance and counseling was willingly accepted in schools, many of which were already doing so on an informal basis (O'Connor \& Walshe, 1979).

Since the late 1970s, the role of guidance counselors in schools has received a fair amount of attention in research studies (see Chamberlain \& Delaney, 1977; Ireland. Department of Education, 1987; McCarthy, 1985; O'Brien, Tuite, McDonagh, \& Deffely, 1982-83; O'Connor \& Walshe, 1979; O'Leary \& Adams, 1986; O'Leary \& McCay-Morrissey, 1987; Ryan, 1993). There is considerable variation in the nature and size of the samples on which studies were based. For example, the range of studies includes a relatively small-scale local study in 18 Cork schools (O'Leary \& McCay-Morrissey, 1987), a major study of subject provision, choice, and allocation involving a nationally representative sample of second-level schools in which 68 counselors provided information about their work (Hannan, Breen, Murray, Watson, Hardiman, s O'Higgins, 1983), and a study based on a sample drawn from the membership of the Institute of Guidance Counselors involving 340 counselors Ryan, (1993). A consistent finding of research studies is that educational, vocational, and career counseling is the main activity of guidance counselors (Hannan et al, 1983; McCarthy, 1985; 0'Leary s McCay-Morrissey, 1987; Ryan, 1993) While most of the 340 counselors in a survey conducted by Ryan (1993) also indicated that they regarded personal counseling as a major part of their work, the amount of time they devoted to this activity varied in different parts of the country. From Ryan's (1993) data, it is clear that many counselors provide advice to students on a wide range of problems relating to family, sex, social and emotional development, bullying, unreasonable academic expectations, and alcohol and drug abuse.

The role and responsibility of the counselor in educational institutions is much complex as compared to other organizations. There are legal, professional and organizational issues involved in counseling with children. Students counseling was first developed and implemented in England and Wales in mid-1960s. But progress in this regard has been very slow due to limited funds. Schools also utilize the services of external agencies like Child and Adolescent Mental Health Services (CAMHS) and the National Society for the Prevention of Cruelty to Children (NSPCC) for better quality and professional expertise. Services of counselors are especially required for Special Education Institutions to meet the specific needs of special children. Despite the high significance of the subject, there was very little research done for counseling in secondary schools since the research survey carried out by NFER in 1998. NSPCC has specially pointed out lack of large scale reliable information on this subject. For effective counseling, availability of suitable private setting is very important for 
confidentiality and the success of counseling process. Funding is a key for setting up and the maintenance of successful counseling service. Another issue is the qualification of counselor. There were cases like in East Sussex Secondary Schools where counseling was being provided by staff with variations in qualifications and experiences.

Academic Counseling faces various difficulties in various contexts, like it is having many difficulties in countries like Saudi Arabia. In King Saud University, faculty comes from different backgrounds. Those hired from countries other than USA, have never experienced credit system. Similarly students come from secondary schools without having adequate knowledge of credit system. Students have to specify their majors in the beginning, but not having sufficient knowledge about various fields of study, they keep changing their majors which create problems. To solve this problem they need the services of academic counselor. In Ireland, history of counseling dates back in 1960 when first educational psychologist was appointed. In the 1983, it was decided that a school having more than 250(threshold extended to 500 later on) students can appoint a counselor on 'ex-quota' basis. It means that if a school wants to appoint counselor it can do so within the overall staff allotment.

\section{Methodology}

Our methodology included thorough review of literature. We generally review the literature through secondary sources includes various publications, journals, articles and periodic reports. Personal visits and document analysis helps to explain the problem focused. To help the organization in its value addition process, this study is conducted in a Govt. run Intermediate level college in the North of Punjab by conducting survey by getting general opinion of students and teachers, just to analyze the problem that either it is prevailing, if so, then what is the root cause according to their opinion regarding their school life and by the help of their responses determining how much public schools are contributing towards the quality of the education and what are the perception of students regarding education system.

\section{Findings and Discussion}

Pakistan is developing country with poor infrastructure, low quality education and lack of financial and material resources. Majority of its population resides in villages where there is lack of educational facilities, guidance and students really do not know what sort of education they should seek. Furthermore, there is lack of educational planning at government level and there is visible saturation in many educational fields like IT, Teaching, Engineering etc. So there is dire need to guide the students at an early stage regarding the line which should he/she adopt for higher studies? There is no culture and institutions of career counseling in our society and student wander from one educational field to other in search of more suitable line for there careers. Moreover, our educational institutions do not hire the services of professional counselors for the guidance of their students. This study can contribute to Educational Policy Makers. Data collected through student counseling could be used for spotting the pitfalls of our education system. We can know what are the specific problems that our students face? What are the ground realities that are hidden from the eye of our policy makers? This paper seeks to identify parameters of value addition for the improvement of our education system and to identify the main areas of problems that our students face. Findings of this paper could be utilized for getting insight into perceptions of our students regarding various components of our education system.

Educational system of Pakistan needs improvement like, one educational system is necessary, here three type of educational system are prevailing. One English medium and Cambridge system, where mostly children of upper class family get educated, second is Urdu medium system where children from middle class family studied. Third one is 'TAT' (a piece of cloth used instead of chairs in poor schools) school system, where student of lower class or have poor family background get education, mostly in villages third type of educational system is prevailing. So Pakistan needs a common education system where each and every student either he belongs to any caste or social family background, they get same education. Syllabus of different subject still the same in lower classes as it was studied in1980's, so policy makers must think on it. Provide up-to-date knowledge to students so that they can compete with students at international level. Pakistan have huge force of youth as compared to any other country of the world, and the youth is provided with great talent but policy maker of 
this country ruined this talent, they need to give a pathway to explore and polish the talent of such a huge youth force, that surely makes a great change in Pakistan as well as in the world. Student counseling at secondary level is very important, because it is the level where student needs a way to choose. Where they should go, someone must be there to guide them. So policy maker must have to devise such a strategy that they can use the hidden talent for the benefit of Pakistan and the world as well The demand for Pakistani labor has been increase since 1980's, Gulf countries, USA and UK are the main markets for Pakistani Labor and young talent.

\section{Conclusion}

At times usual ways of handling problems are not working for some reason and one feels stuck! Counseling helps students to discuss and understand their problem and create different strategies to cope with that problem. Period of life change like being in college may bring new stress and problems that have many sides and are not easily solved. Counseling can help clients understand the different sides of their problems, so that their situation may be improved. When life becomes difficult, lots of little things go wrong for someone, it may become difficult to feel hopeful or have a positive outlook. Counseling can help students understand the impact of tough situations have had on their feelings and develop strategies to create a more hopeful perspective. Most people struggle to overcome bad habits (behaviors that we seem to repeat over and over even though they may lead to problems for example: procrastination, angry outbursts, drinking too much, etc). Counseling provides a safe space to learn more about overcoming these habits by using strategies that have been shown to help others in similar situations. Seeking help from professional experienced helpers may feel as helping our selves, by taking steps to improve life and influence life situation one can create many differences.

Counseling can help one learn more about own self by helping and understanding his own strengths and learning how to use those strengths to grow in other areas. Counseling can helps in setting goals for college life and future career. It can help in understanding strengths and areas of growth as a student. It can also help that how stress and emotional difficulties may interfere with one's abilities to focus on studies and help in developing better way to cope with that problem. The study concluded that there is a need to considerably improve the content and quality of personal and social development education and pastoral-care programs in schools. These goals are given very high priority by school leavers, and rather low satisfaction marks result for their schools' (Hannan \& Shortall, 1991).

\section{References}

Chamberlain, J. (1983). Guidance and counselling in the Republic of Ireland. Personnel and Guidance Journal, $61,479-482$.

Chamberlain, J. \& Delaney, O. (1977). Guidance and counselling in Irish schools. British Journal of Guidance and Counselling, 5(1), 49-64.

Hannan, D. F., Breen, S., Murray, B., Watson, D., Hardiman, N., O'Higgins, K. (1983). Schooling and sex roles: Sex differences in subject provision and student choice in Irish.

Hannan, D. F. \& Shortall, S. (1991). The quality of their education: School leavers' views of educational objectives and outcomes. Dublin: Economic and Social Research Institute.

Ireland Department of Education (1987). Report of the School Guidance Committee, Dublin.

McCarthy, J. (1993). Guidance and counselling: A unifying theme. CONASC, 1(2), 14-17.

McCarthy, J. (1985). A survey of guidance, counselling and assessment in the Cork COMTEC area. Cork: Community Training and Employment Consortium.

O'Connor, T. P. \& Walshe, J. (1979). Guidance in Ireland: New directions. Compass, 8(2), 4-22.

O'Brien, R., Tuite, F., McDonagh, P. \& Deffeley, T. (1982-83). The role of the counsellor. Institute of Guidance Counsellors Journal, 7, 31-35.

O'Leary, E. \& Adams, M. (1986). The guidance counsellor in the classroom. Institute of Guidance Counsellors Journal, 12, 28-31.

O'Leary, E., McCay-Morrissey, T. (1987). Time spent by the guidance counsellor on various duties. Institute of Guidance Counsellors Journal, 13, 25-30.

Ryan, L. (1993). Counselling the adolescent in a changing Ireland. Dublin: Institute of Guidance Counsellors. post-primary schools. Dublin: Economic and Social Research Institute. 